\title{
Tissue Engineered Vascularized Patient-Specific Temporomandibular Joint Reconstruction in a Yucatan Pig Model
}

\author{
Shelly Abramowicz ${ }^{1}$, Sarah Jo Crotts ${ }^{2}$, Scott J. Hollister ${ }^{3}$, Steve Goudy ${ }^{4}$
}

1 Associate Professor in Oral and Maxillofacial Surgery and Pediatrics, Division of Oral and Maxillofacial Surgery, Department of Surgery, Emory University School of Medicine, Associate Chief of Oral and Maxillofacial Surgery, Children's Healthcare of Atlanta, Atlanta, Georgia

2 Research Scientist, Center for 3D Medical Fabrication, Department of Biomedical Engineering, Georgia Institute of Technology, Atlanta, Georgia

3 Professor and Patsy and Alan Dorris Chair in Pediatric Technology, Department of Biomedical Engineering, Georgia Institute of Technology, Atlanta, Georgia

4 Professor and Chief, Pediatric Otolaryngology, Department of Otolaryngology, Emory University School of Medicine, Children's Healthcare of Atlanta, Atlanta, Georgia.

Corresponding Author:

Shelly Abramowicz

1365 Clifton Ave

Building B, Suite 2300

Atlanta, GA 30322

404.778.4555

Email:sabram5@emory.edu 


\begin{abstract}
Purpose: Pediatric temporomandibular joint (TMJ) reconstruction occurs as a result of acquired, developmental, and/or congenital conditions. Current pediatric reconstruction options are limited. The aim of this project was to develop a proof of principle porcine model for a load bearing, customized 3-dimensional (3D) printed and BMP2-coated scaffold implanted in a pedicled (temporal) flap as a regenerative approach to pediatric TMJ mandibular condyle reconstruction.
\end{abstract}

Materials and Methods: Scaffolds were custom designed and 3D printed based on porcine computed tomography and absorbed with BMP2. Two operations occured: (1) implantation of scaffold in temporalis muscle to establish vascularity, and six weeks later, (2) unilateral condylectomy and rotation of the vascularized scaffold (with preservation of superficial temporal artery) onto mandibular ramus defect and secured with titanium screws. At 6 months post-implantation, the pigs were sacrified. The experimental side (muscle-scaffold) and the control side (unoperated condyle) were individually harvested at 6 months and evaluated by clinical, mechanical, radiographic, and qualitative/histologic methods.

Results: Scaffolds maintained physical properties similar in appearance to unoperated condyles. The vascularized scaffolds had bone formation at edges and adjacent to scaffold-bone interface. New bone was visible in scaffold. Condyle height on the reconstructed side was $68 \%$ and $78 \%$ of the control side. Reconstructed condyle stiffness was between $20 \%$ and $45 \%$ of the control side.

Conclusion: In our porcine model, customized 3D printed TMJ scaffolds impregnanted with BMP2 and implanted in and pedicled on temporalis muscle has the ability to (1) reconstruct a TMJ defect model, (2) maintain appropriate condylar height and upper airway diameter, and (3) generate new bone, without impacting functional outcomes. 


\section{INTRODUCTION}

The pediatric temporomandibular joint (TMJ) may require reconstruction as a result of acquired (eg juvenile idiopathic arthritis, JIA (Abram), trauma), or congenital (hemifacial microsomia, HFM) (Kaban 1988) conditions[1,2]. The condyle is the primary growth center of the mandible; skeletal growth and development of the condyle are necessary for appropriate function and esthetics. Current options for pediatric TMJ reconstruction are usually only considered in late adolescence and include distraction osteogenesis (DO), autologous reconstruction [i.e. costochondral graft (CCG) or free fibula bone flap (FFF)], and total alloplastic TMJ replacement (TJR). DO requires a long activation period, can fail with premature bone consolidation and may result in poor occlusion and asymmetry[3,4]. DO may not be applicable in cases where the condyle ramus unit (RCU) is missing (eg HFM). Autologous reconstruction with CCG depends on surrounding recipient tissues for revascularization. Postoperatively, some resorption of CCG will likely occur with potential for complete resorption. FFF usually does not resorb, but the donor defects can be significant. FFF may not routinely be considered in young children due to small caliber of vessels $[5,6]$ and technical challenges. TJR is not often considered in children because of remaining craniofacial growth potential and likelihood that they would have to be replaced at least once during the child's lifetime[7,8]. Due to the current reconstructive limitations, a better reconstructive solution is needed for children who are missing their TMJ.

Developing a regenerative solution that harnesses the body's ability to form bone and utilizes a local blood supply, without significant donor defect, would be ideal. In early engineering experiments, pre-fabricated TMJ construct implantation with free flaps have been attempted[9], but without reliable vascularization. The ability to rotate a local vascularized flap into a TMJ defect eliminates the complexity of implanting a free flap. We have previously accomplished the design, 3-dimensional (3D) printing, and bone morphogenic protein (BMP)2 delivery necessary to create customized TMJ scaffold/biologic constructs in both large (Yucatan minipig and Yorkshire domestic pig) and small animal models[10-13] Specifically, we: (1) designed and optimized scaffolds to meet patient specific anatomy and functional requirements [10, 13], (2) printed a 3-dimentional customized scaffold designs using polycaprolactone (PCL)[14], (3) delivered BMP2 and BMP2/EPO combinations[11, 12], and (4) demonstrated bone and vascular growth in large and small animal models[10-13]. However, this technology has not been used to reconstruct a pediatric TMJ.

The aim of this project was to develop a large animal model for a load bearing, customized, 3D printed scaffold with BMP-2 and embedded in a vascularized pedicled (temporal) flap as a regenerative approach to pediatric TMJ mandibular condyle reconstruction.

\section{MATERIALS AND METHODS}

\section{Animal Model}

Three male Yucatan minipigs (age 6 months) were used during this experiment. The study was performed in accordance with the regulations and approval of the Institutional Animal Care and Use Committee (internal study code\# GT39P) of the T3 Laboratories Inc. in Atlanta, GA and Georgia Institute of Technology. The animals were housed for five days prior to surgery to become acclimated to housing and diet. Throughout the experiment duration, they 
were monitored daily for general appearance, biologic functions (eg food and water intake and elimination, weight, and activity) and when applicable, signs of pain.

This experiment consisted of two operations which took place under general anesthesia. During the first operation, the scaffold was implanted in the temporalis muscle in order to become vascularized by the temporalis artery. Animals were then allowed to eat, function, and grow normally. Six weeks later, the second operation occurred. Via a hemicoronal incision, the tempoparietal pedicle-scaffold was identified via doppler of temporalis muscle. A unilateral (left side) condylectomy took place and the vascularized scaffold (with preservation of superficial temporal artery) was rotated inferiorly 180 degrees into mandibular ramus and secured with screws (KLS Martin). At end of experiment, animals were sacrificed. The experimental side (scaffold-pedicle) and the control side (unoperated condyle) were individually analyzed (Figure 1).

\section{Scaffold construction}

A customized (pig)-specific porous scaffold of a mandibular condyle was designed directly from a computed tomography (CT) scan of a 6-month old Yucatan minipigs. A Schwarz $P$ triply periodic minimal surface (TPMS) of $40 \%$ volume fraction was generated within the mandibular condyle anatomy using image-based design methods[10]. The Schwarz P TPMS microstructure was chosen as it is known to provide an optimal balance between mechanical stiffness and mass transport to support load bearing and tissue growth[15]. An integrated collar with screw holes was created to secure the scaffold to the remaining ramus with titanium screws. The resulting image-based condyle design was converted into STL format using Materialise Mimics ${ }^{\mathrm{TM}}$ (www.materialise.com). The mandibular condyle scaffold was 3D printed from polycaprolactone ( $\mathrm{PCL})$, a resorbable biopolymer, using a laser sintering approach previously described[10, 14, 16, 17]. The resulting scaffold was fit to a 3D Printed model of a Yucatan Minipig mandible (Figure 2).

\section{Scaffold insertion}

Scaffolds were sterilized in ethylene oxide, then soaked in a solution of $1 \mathrm{mg} \mathrm{BMP-2}$ in the operating room. During the first operation, the scaffold was implanted in the temporalis muscle under the superficial temporal artery in order to become vascularized (Figure 3a) . After 6 weeks in situ (in muscle), the scaffold (now vascularized within the temperoparietal flap) was rotated into the created ramus defect and attached to the ramus with titanium screws (Figure $3 b)$. The untreated condyle served as a control. Animals were then allowed to eat, function, and grow normally for 6 months. Animals were then sacrificed.

\section{Radiologic Analysis}

Six months after condyle reconstruction, animals were sacrificed and computer tomography (CT) scans were taken. MicroCT scans and mechanical compression tests were then performed on reconstructed (experimental) condyle and contralateral (non-operated, e.g. control) condyles. CT scans were used to compare new condyle to control condyle by calculating condyle height, condyle volume, and condyle bone volume fraction (total bone 
volume/condyle volume). Retrieved regenerated scaffolds with new condyle and retrieved contralateral mandibular condyles were tested in mechanical compression along the mediallateral condyle polls (Figure 4). Resulting load-displacement curves were used to calculate geometric stiffness (load/displacement) from the linear portions of the load-displacement curves. The resected condyle represents condyle stiffness for a Yucatan pig at 7 months of age (6 months old plus 1 month from flap implantation to flap rotation). The contralateral condyle represents condyle stiffess for the Yucatan pig at 13 months of age (6 months old at time of flap implantation, 1 month for flap growth, 6 months until end of experiment).

\section{Histological Analysis}

Each specimen was trimmed and embedded in methyl methacrylate. One ground section and three thins sections were taken from the approximate center of the specimen (Figure 5). They were stained (toluidine blue, hematoxylin\&eosin, and Safranin O). All sections were evaluated microscopically to determine: (1) bone formation within the construct, (2)regeneration of cartilage at the articulating surface, (3) vascularization, and (4) cellular response to the implants. Photomicrographs were taken as needed to illustrate the findings.

\section{RESULTS}

\section{Clinical Evaluation}

One animal developed an infection at the implant site due to thin skin adjacent to the surgical site and had to be euthanized prior to conclusion of study. Two animals were allowed to survive for 6 months (weight $32.4 \mathrm{~kg}$ and $29.6 \mathrm{~kg}$ ). They demonstrated normal bodily functions (mastication, food and water intake and elimination), activities, and weight gain $(11.8 \mathrm{~kg}$ and $13.4 \mathrm{~kg}$ ) during that time.

\section{Radiologic Evaluation}

Models reconstructed from the CT scans demonstrated bony regrowth of the mandibular condyle that had been resected (Fig. 6). Reconstructed condyles had $78 \%$ (Figure $6 \mathrm{a}$ ) and $68 \%$ (Figure $6 \mathrm{~b}$ ) of the height of contralateral control condyles. From microCT scans, reconstructed condyle has $67 \%$ and $36 \%$ of the total condylar volume of the contralateral control condyles. Finally, the bone volume fraction (total bone volume/condyle volume) for the reconstructed condyles were $107 \%$ and $105 \%$ of the contralateral control condyle bone volume fraction.

\section{Scaffold Mechanical Evaluation}

Load-displacement curves ( $n=5,2$ regenerated condyles, 2 contralateral/non-operated condyles, and 1 condyle resected at the time of flap rotation) show that the regenerated condyles had lower geometric stiffness than the contralateral or resected condyle (Fig. 7). Regenerated condyles had $36 \%$ to $77 \%$ of the stiffness of the resected condyles and $20.6 \%$ to $46 \%$ of the stiffness of the contralateral condyles. The resected condyle stiffness had $57 \%$ of the contralateral condyle stiffness. The toe region at the beginning of the load displacement curve results from compression of soft tissue surrounding the bony condyle. 
Thin sections from the approximate center of the neo-condyles, contralateral controls, and mandibular condyle scaffolds were evaluated microscopically. The control and experimental condyles were compared. The results demonstrated that there was new bone in a few focal within the implant (figure 8 ) and that the implant was partially incorporated in newly formed bone (figure 9). There was no cartilage regeneration. Blood vessels were visualized at surface of implant material (fig 10). Vascularized fibrous tissue (fig 11) with macrophage and giant cell infiltrates were found to be associated with the implant material.

\section{DISCUSSION}

The aim of this project was to develop a model for a load bearing, customized (porcine), 3D printed and expandable scaffold, absorbed with BMP-2 based on a pre-vascularized pedicled (temporal) flap as a regenerative approach to pediatric TMJ mandibular condyle reconstruction.

In our project, we compared CT scan of the reconstructed condyles to the un-operated (control) TMJ. This revealed that the reconstructed 3D printed PCL TMJ BMP2 maintained mandibular height, condylar volume, and bone volume fraction. These results are similar to outcomes reported by Bhumiratana et al.[18] who reported pre-seeding decellurarized bovine bone condyle scaffolds with 100 to 150 million adipose derived stem cells for 3 weeks prior to implantation. This technology, consisting of cell therapy outside of cells derived from the patient in the operating room, faces a significant regulatory hurdle that would make it difficult to translate such an approach for pediatric mandibular condyle reconstruction. However, the ability to design and fabricate a custom patient-specific scaffold via a custom device exemption or expanded access may enable this approach to be clinically translated for a pediatric patient population.

In our study, we used 3D printing technology to form the scaffold of condyles. This technology is being used in many facets of pediatric and adult regenerative medical therapies (i.e. ear and airway reconstruction). Previous studies on 3D tissue regeneration are performed on small animal models, but few use large animal models that mimic human tissue regeneration. Limitations in 3D printed constructs exist with scaffold vascularization[19] and integration by the patient. By combining 3D printing technology with BMP2 bone regeneration technology, we showed that BMP2 impregnated TMJ 3D printed scaffolds are able to regenerate a functional TMJ with quantifiable bone measurements using a vascularized 2-step temporalis flap approach.

Regenerative solutions to bone loss in adults have already been accomplished in spine and maxillary surgery using BMP2[20, 21]. However, a regenerative solution in children is needed. An ideal TMJ reconstruction would allow for stable biological properties necessary for daily function while bone regeneation is occuring. Using our protocol, the functional outcomes of eating and weight gain were maintained by the pigs. We demonstrated that the reconstructed TMJ was able to preserve height and volume necessary for daily activities. Functionally, weight or diet did not change following surgery, showing that the surgical intervention did not interfere with regular activites of daily living.

The integration of the temporalis muscular flap to vascularize the regenerative scaffold is based on the the superficial temporal artery blood supply. This method is currently routinely used for head and neck reconstruction [22](Dallan). Most commonly, this flap is used to cover 
auricular prostheses that are implanted to address microtia[23] (yang 2009). Previous models stated that development of vascularization has been challenging[19, 24] (Abukawa 2003, 2004). Using our juvenile mini-pig TMJ condylectomy model, 3D printed osteoinductive PCL scaffold impregnated with BMP2 was used in a two step manner. Our study demonstrated partial cell and fibrous tissue infiltration of the constructs implanted in the temporalis muscle. The tissue present was predominantly vascularized fibrous tissue, with macrophage and giant cell infiltrates associated with the implant material. Blood vessels were visualized at surface of implant material demonstrating angiogenesis and recruitment of blood vessels necessary for bone formation. These results suggest that the implants were likely vascularized. Thus, our protocol of using a pedicled blood supply, proved to be efficacious. Lastly, our protocol demonstrated new bone formation in the neo-condyles. This bone served as initial matrix for additional bone formation and allowed normal mandibular function. Additional large animal studies will further delineate the durability and long-term (>1 year) bone regeneration and functional outcomes. Current limitations in this pilot study is the loss of one animal and the 6 month time point, whereas additional bone ingrowth is expected to occur as the PCL scaffold slowly resorbs over a several year time frame. A challenge for pre-fabricated flap approaches going forward will be delivering appropriate bone and vascular biologic signals to develop bone and vascular tissue in the flap prior to rotation. Addressing this challenge will require experimentation using a variety of biologics and delivery vehicles within the load bearing scaffolds.

In summary, we demonstrated that in our porcine model, temporalis flap-based 3D printed PCL TMJ with BMP2 has the ability to (1) reconstruct a TMJ defect model, (2) maintain appropriate condylar height and (3) generate new bone without impacting functional outcomes. Bone formation in the flap prior to rotation was minimal. We are exploring other BMP2 delivery methods from the 3D printed scaffold, including a PolyEthyleneGlycol (PEG) based hydrogel system to allow controlled BMP2 delivery. Futhermore, the scaffold structure could be optimized to enhance its load bearing capability.

\section{ACKNOWLEDGEMENTS}

This study was supported by a pilot grant from the Regenerative Engineering and Medicine center, a joint collaboration between Emory University and Georgia Institute of Technology. We would like to thank Mr. Ryan Akman for assistance with mechanical testing and microCT scanning as well as Dr. Harsha Ramaraju for assistance with the BMP2 adsorption on the scaffold. T3 Labs (gcmiatl.com/preclinical-testing-and-training) for animal surgical support and animal CT scanning. 


\section{REFERENCES}

1. Abramowicz S, Kim S, Prahalad S, Chouinard AF, Kaban LB: Juvenile arthritis: current concepts in terminology, etiopathogenesis, diagnosis, and management. Int J Oral Maxillofac Surg 45:801, 2016

2. Kaban LB, Moses MH, Mulliken JB: Surgical correction of hemifacial microsomia in the growing child. Plast Reconstr Surg 82:9, 1988

3. Dolanmaz D, Ozturk K, Ilik MB, Celik M: Reconstruction of condyles by transport distraction osteogenesis: 3 case report with complication management. J Stomatol Oral Maxillofac Surg 119:348, 2018

4. Neelakandan RS, Bhargava D: Transport distraction osteogenesis for maxillomandibular reconstruction: current concepts and applications. J Maxillofac Oral Surg 11:291, 2012

5. Cleveland EC, Zampell J, Avraham T, Lee ZH, Hirsch D, Levine JP: Reconstruction of Congenital Mandibular Hypoplasia With Microvascular Free Fibula Flaps in the Pediatric Population: A Paradigm Shift. J Craniofac Surg 28:79, 2017

6. Markiewicz MR, Ruiz RL, Pirgousis P, Bryan Bell R, Dierks EJ, Edwards SP, Fernandes R: Microvascular Free Tissue Transfer for Head and Neck Reconstruction in Children: Part I. J Craniofac Surg 27:846, 2016

7. Cascone P, Vellone V, Ramieri V, Basile E, Tarsitano A, Marchetti C: Reconstruction of the Adult Hemifacial Microsomia Patient with Temporomandibular Joint Total Joint Prosthesis and Orthognathic Surgery. Case Rep Surg 2018:2968983, 2018

8. Polley JW, Girotto JA, Fahrenkopf MP, Dietze-Fiedler ML, Kelley JP, Taylor JC, Lazarou SA, Demetriades NC: Salvage or Solution: Alloplastic Reconstruction in Hemifacial Microsomia. Cleft Palate Craniofac J 1055665618817669, 2018

9. Torroni A: Engineered bone grafts and bone flaps for maxillofacial defects: state of the art. J Oral Maxillofac Surg 67:1121, 2009

10. Hollister SJ, Flanagan CL, Morrison RJ, Patel JJ, Wheeler MB, Edwards SP, Green GE: Integrating Image-Based Design and 3D Biomaterial Printing to Create Patient Specific Devices within a Design Control Framework for Clinical Translation. ACS Biomaterials Science \& Engineering 2:1827, 2016

11. Patel JJ, Flanagan CL, Hollister SJ: Bone Morphogenetic Protein-2 Adsorption onto Polyvarepsilon-caprolactone Better Preserves Bioactivity In Vitro and Produces More Bone In Vivo than Conjugation Under Clinically Relevant Loading Scenarios. Tissue Eng Part C Methods 21:489, 2015

12. Patel JJ, Modes JE, Flanagan CL, Krebsbach PH, Edwards SP, Hollister SJ: Dual Delivery of EPO and BMP2 from a Novel Modular Poly-varepsilon-Caprolactone Construct to Increase the Bone Formation in Prefabricated Bone Flaps. Tissue Eng Part C Methods 21:889, 2015

13. Smith MH, Flanagan CL, Kemppainen JM, Sack JA, Chung H, Das S, Hollister SJ, Feinberg SE: Computed tomography-based tissue-engineered scaffolds in craniomaxillofacial surgery. Int J Med Robot 3:207, 2007

14. Williams JM, Adewunmi A, Schek RM, Flanagan CL, Krebsbach PH, Feinberg SE, Hollister SJ, Das S: Bone tissue engineering using polycaprolactone scaffolds fabricated via selective laser sintering. Biomaterials 26:4817, 2005

15. Jung $Y$, Torquato S: Fluid permeabilities of triply periodic minimal surfaces. Phys Rev E Stat Nonlin Soft Matter Phys 72:056319, 2005

16. Zopf DA, Hollister SJ, Nelson ME, Ohye RG, Green GE: Bioresorbable airway splint created with a three-dimensional printer. N Engl J Med 368:2043, 2013

17. Zopf DA, Mitsak AG, Flanagan CL, Wheeler M, Green GE, Hollister SJ: Computer aided-designed, 3-dimensionally printed porous tissue bioscaffolds for craniofacial soft tissue reconstruction.

Otolaryngol Head Neck Surg 152:57, 2015 
18. Bhumiratana S, Bernhard JC, Alfi DM, Yeager K, Eton RE, Bova J, Shah F, Gimble JM, Lopez MJ, Eisig SB, Vunjak-Novakovic G: Tissue-engineered autologous grafts for facial bone reconstruction. Sci Transl Med 8:343ra83, 2016

19. Abukawa H, Shin M, Williams WB, Vacanti JP, Kaban LB, Troulis MJ: Reconstruction of mandibular defects with autologous tissue-engineered bone. J Oral Maxillofac Surg 62:601, 2004 20. Chenard KE, Teven CM, He TC, Reid RR: Bone morphogenetic proteins in craniofacial surgery: current techniques, clinical experiences, and the future of personalized stem cell therapy. J Biomed Biotechnol 2012:601549, 2012

21. Lykissas M, Gkiatas I: Use of recombinant human bone morphogenetic protein-2 in spine surgery. World J Orthop 8:531, 2017

22. Dallan I, Lenzi R, Sellari-Franceschini S, Tschabitscher M, Muscatello L: Temporalis myofascial flap in maxillary reconstruction: anatomical study and clinical application. J Craniomaxillofac Surg 37:96, 2009

23. Yang SL, Zheng JH, Ding Z, Liu QY, Mao GY, Jin YP: Combined fascial flap and expanded skin flap for enveloping Medpor framework in microtia reconstruction. Aesthetic Plast Surg 33:518, 2009

24. Abukawa H, Terai H, Hannouche D, Vacanti JP, Kaban LB, Troulis MJ: Formation of a mandibular condyle in vitro by tissue engineering. J Oral Maxillofac Surg 61:94, 2003 


\section{FIGURES}

Figure 1: sequence of events

Operation 1:
establish vascularization

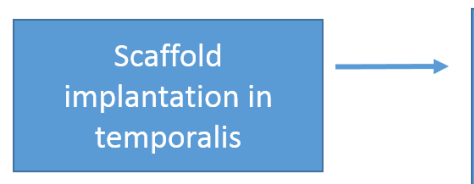

Operation 2: bone formation/integration
Control Group

(unoperated

condyle)
Condylectomy,

scaffold-pedicle

rotation, scaffold implantation

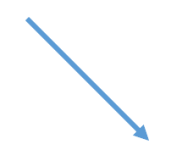

(scaffold-pedicle)

Figure 2: Mandibular condyle scaffold with collar fixation. (a) Design showing repeated Schwartz P microstructure outlined in red (b) 3D printed PCL porous scaffold made of Schwartz P TPMS microstructure with collar fixation fit (outlined in red) on 3D printed Yucatan mandible

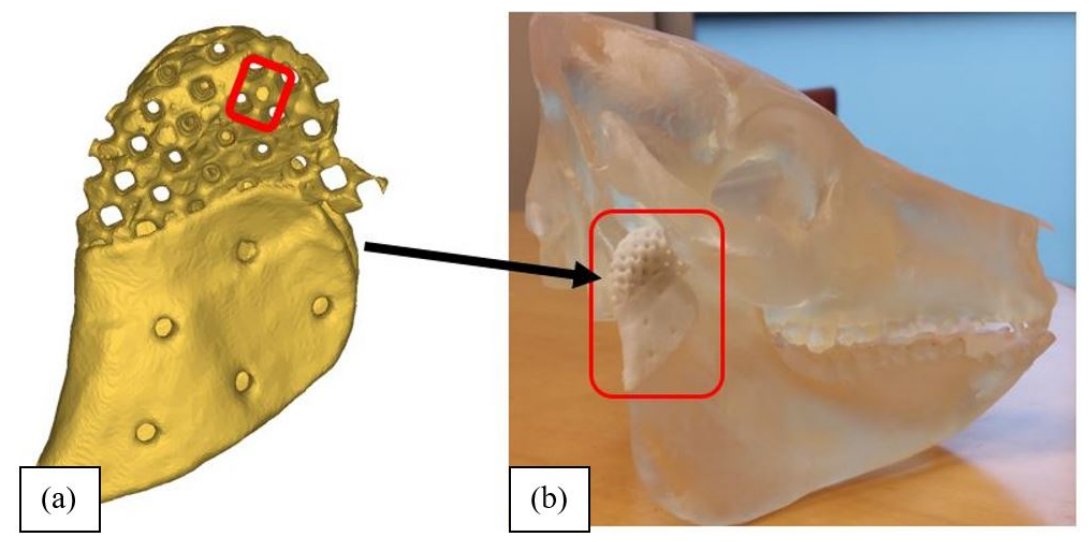


bioRxiv preprint doi: https://doi.org/10.1101/2020.01.09.900746; this version posted January 10, 2020. The copyright holder for this preprint (which was not certified by peer review) is the author/funder. All rights reserved. No reuse allowed without permission.

Figure 3: Two stage surgery. Initial scaffold implantation in temporalis muscle (a). Scaffold flap construct (blue star) after rotation to ramus (yellow star) (b).
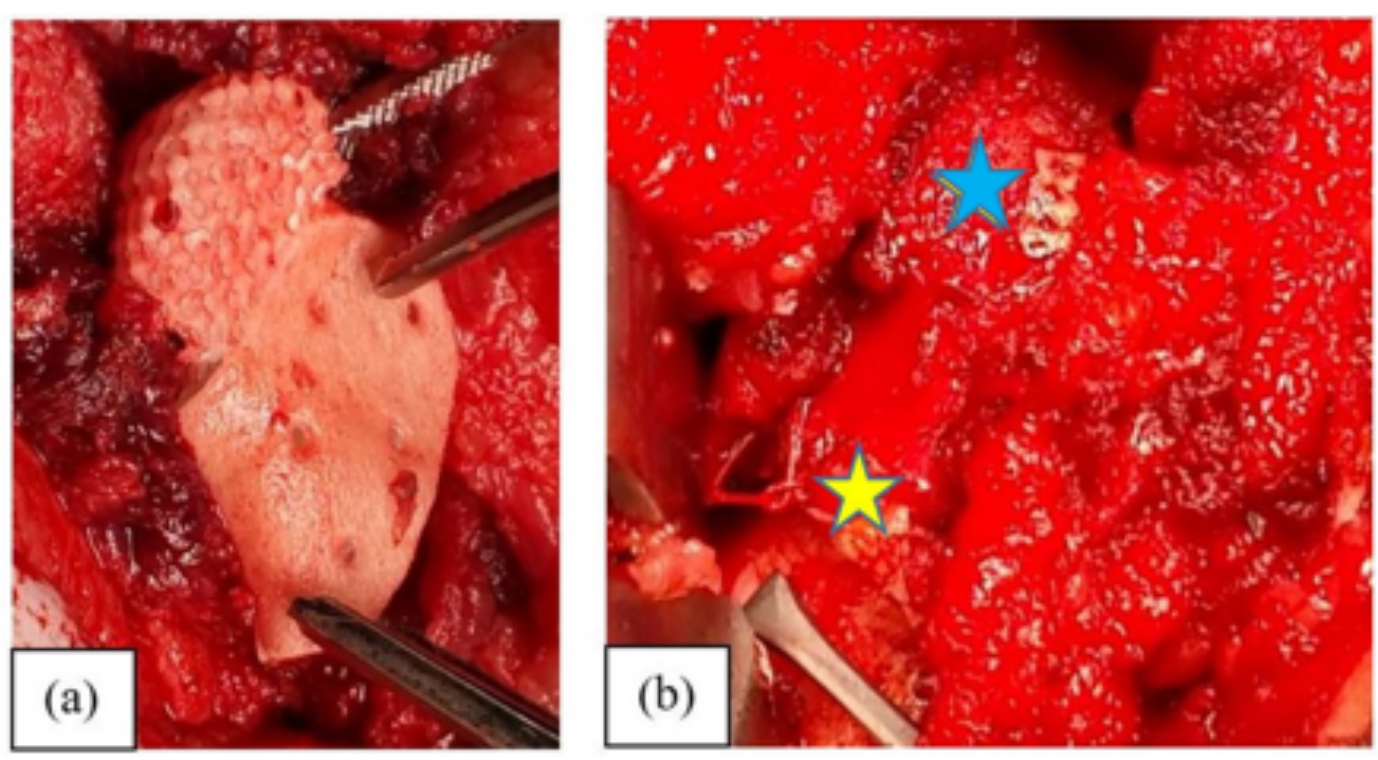
bioRxiv preprint doi: https://doi.org/10.1101/2020.01.09.900746; this version posted January 10, 2020. The copyright holder for this preprint (which was not certified by peer review) is the author/funder. All rights reserved. No reuse allowed without permission.

Figure 4. Example of mechanical compression testing (a) Compression along medial-lateral condyle pole of Pig 2. Condyle head, including rotated muscle flap, while remaining mandibular ramus is to the right of the picture. (b) Pig 2 contralateral condyle (non-operated side), tested in compression along medial-lateral pole.
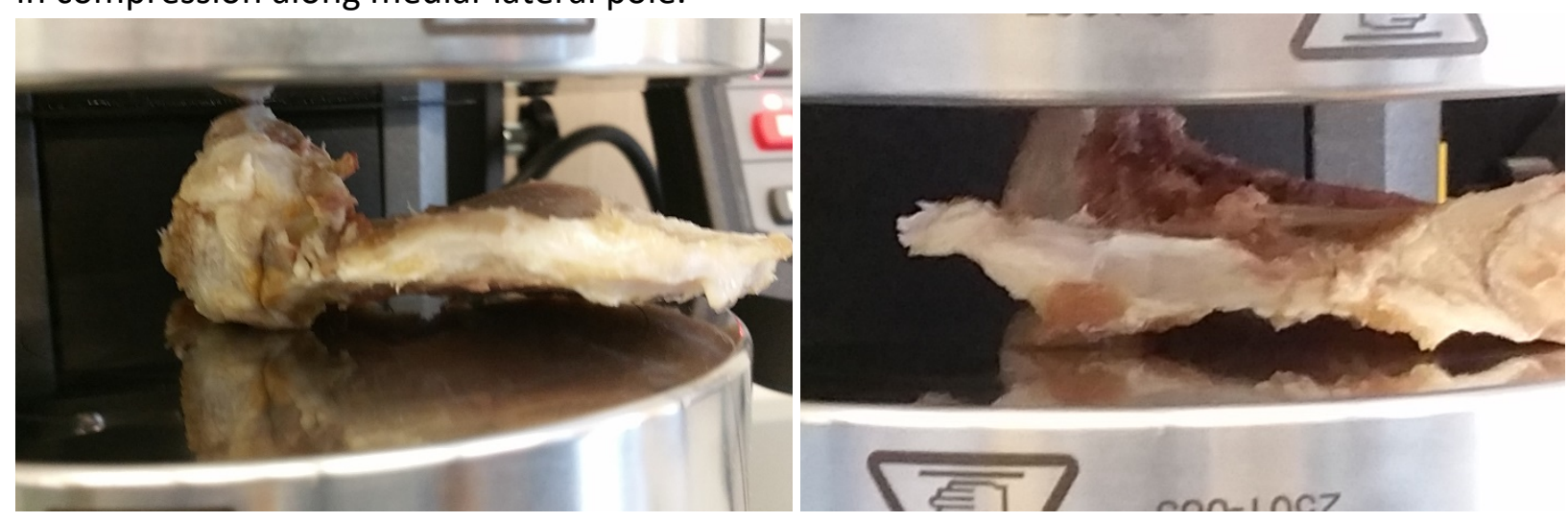

(a)

(b) 
Figure 5: The red dashed lines indicate the plane of section through the implant/condyle.
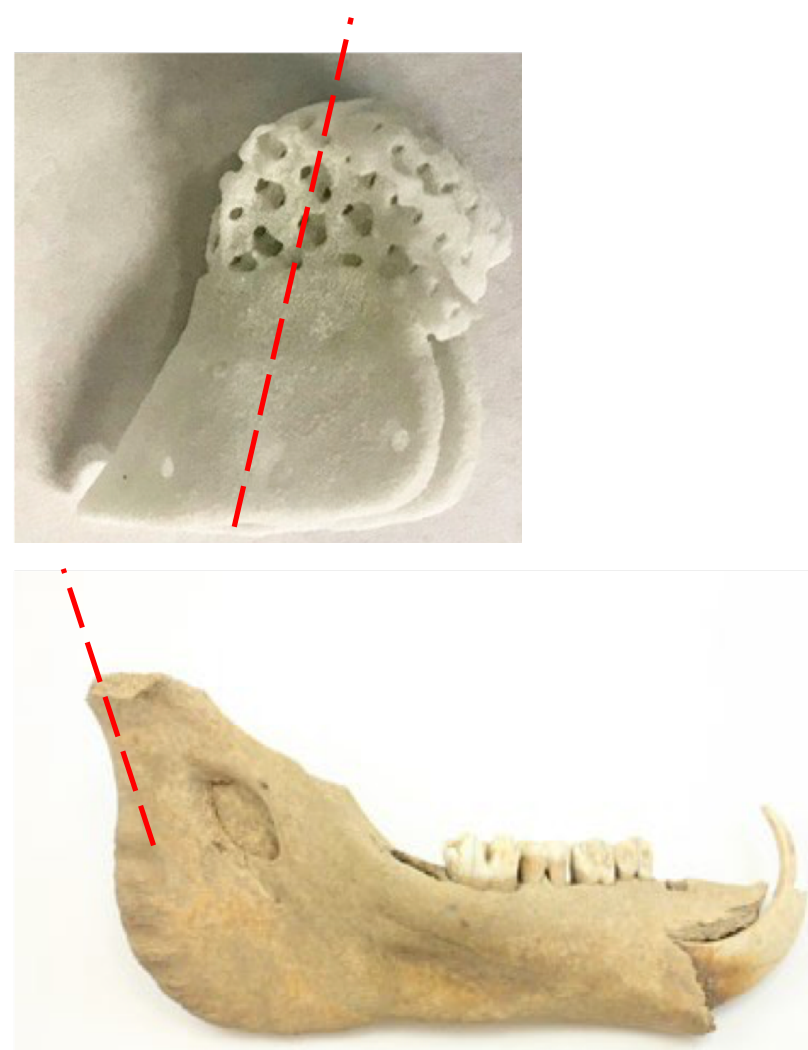
Figure 6: 3D rendering of mandible CT scans taken 6 months after flap rotation and condyle reconstruction. Reconstructed side is outlined in red (a) Animal 1 showing reconstructed and contralateral condyle height. (b) Animal 2 showing reconstructed and contralateral condyle height.
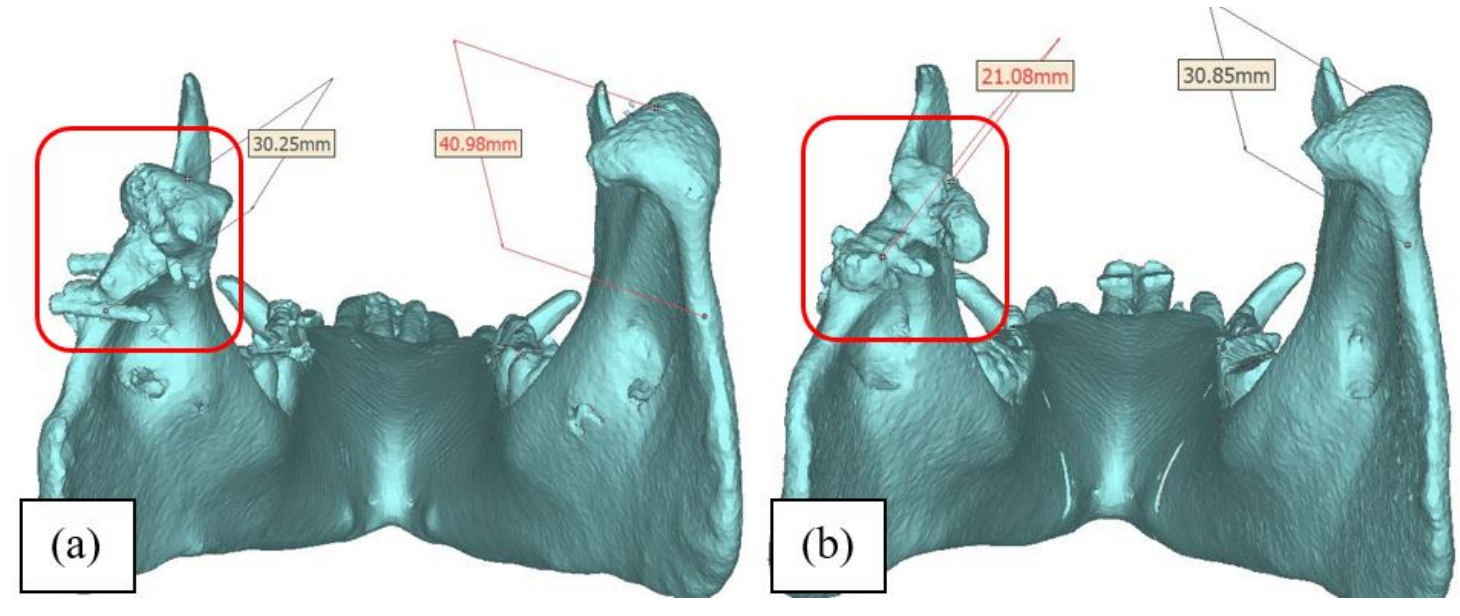
Figure 7: Load-displacement curves for compression testing of regenerated and resected (control) condyles. Linear portion of load-displacement curve represents stiffness of bony region. Regenerated condyles had $36 \%$ to $77 \%$ of the stiffness (S) of the resected condyles and $20.6 \%$ to $46 \%$ of the stiffness of the contralateral condyles. The resected condyle stiffness had $57 \%$ of the contralateral condyle stiffness.

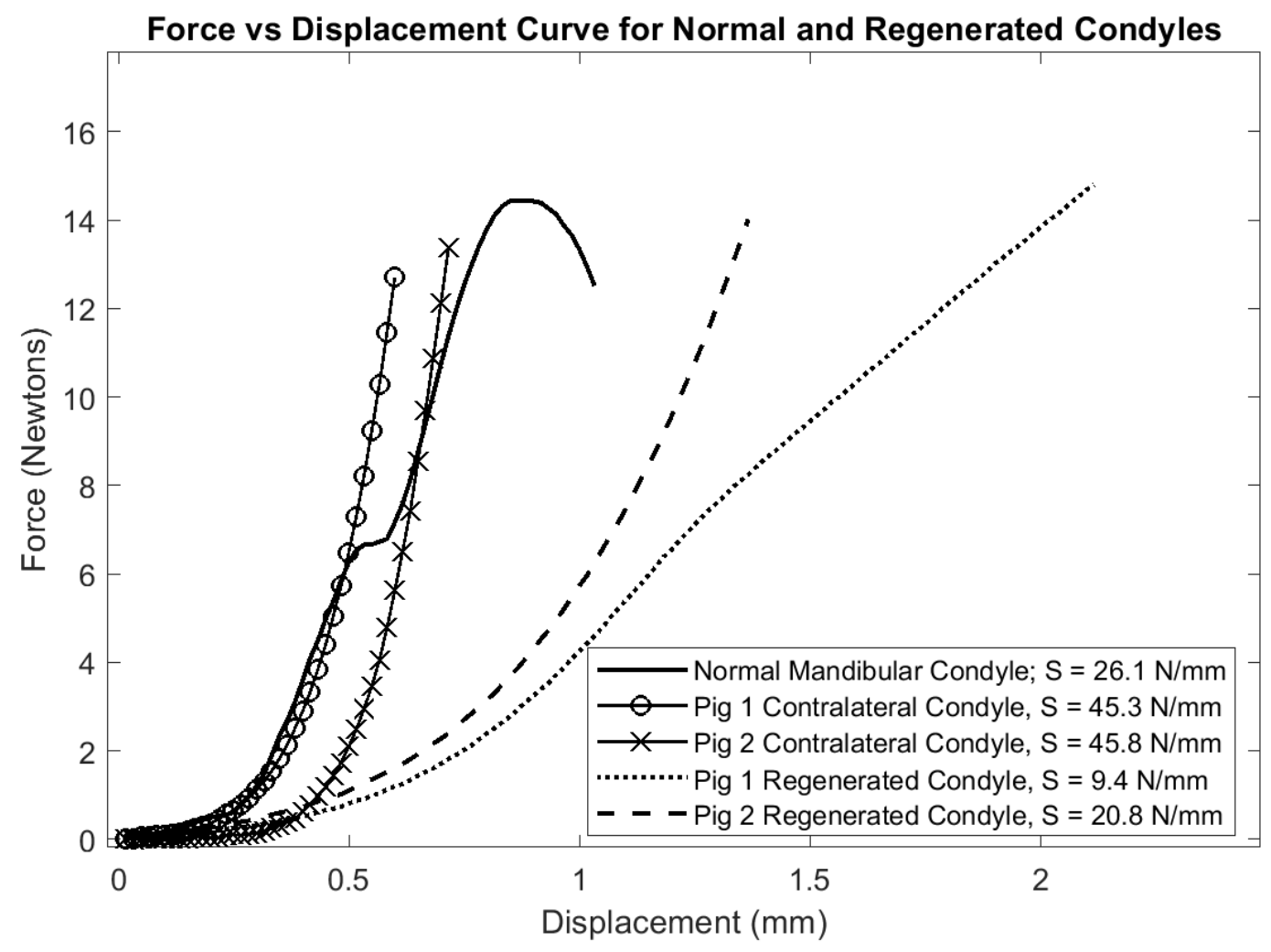


Figure 8: Bone infiltration into the implant (arrow). Toluidine Blue; original magnification, 100X.

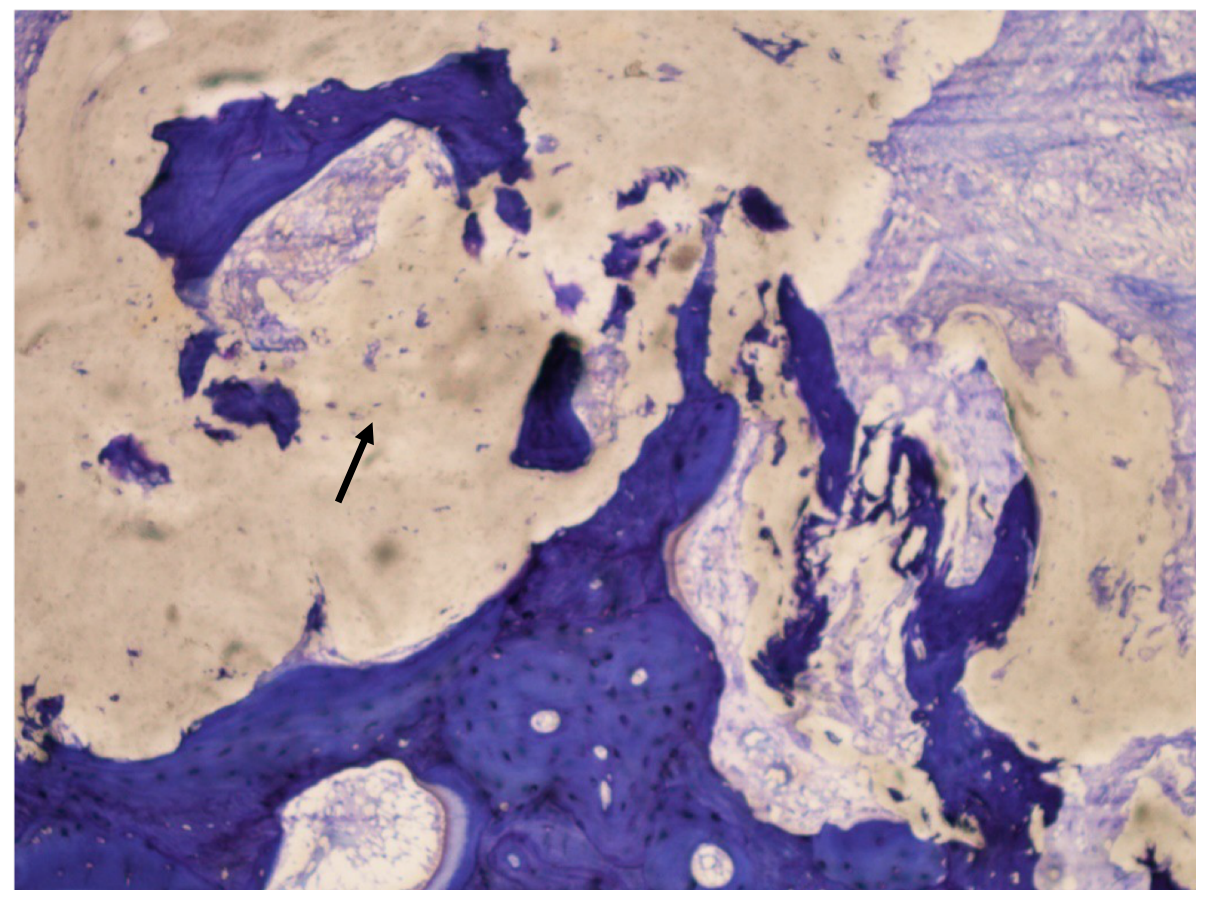


Figure 9: The implant is partially incorporated in newly-formed bone (woven bone, arrow). Toluidine Blue; original magnification, $10 \mathrm{X}$.

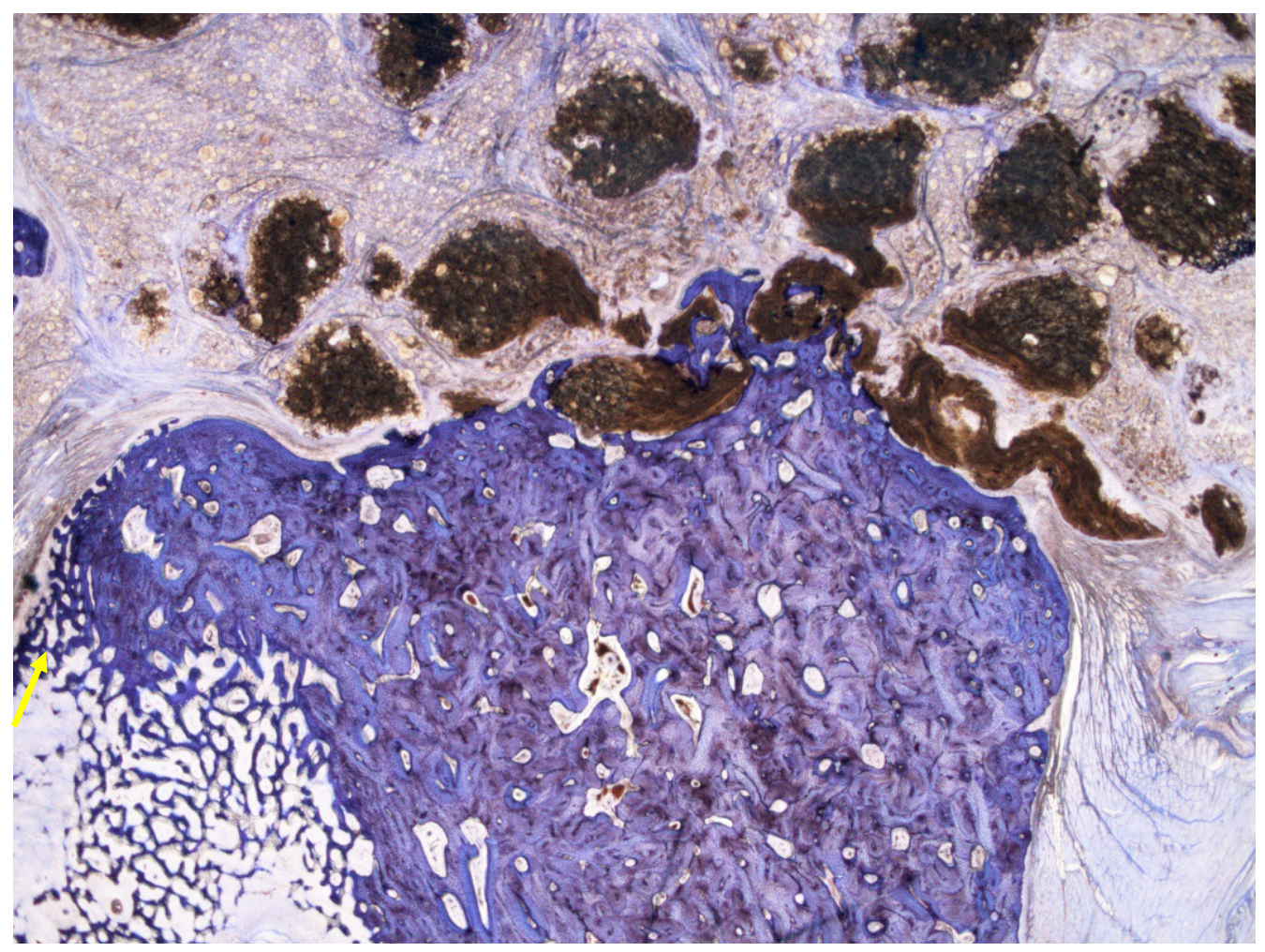


Figure 10: Multiple blood vessels with giant cells (arrows) at surface of implant material (seen as voids). Toluidine Blue; original magnification, $200 \mathrm{X}$

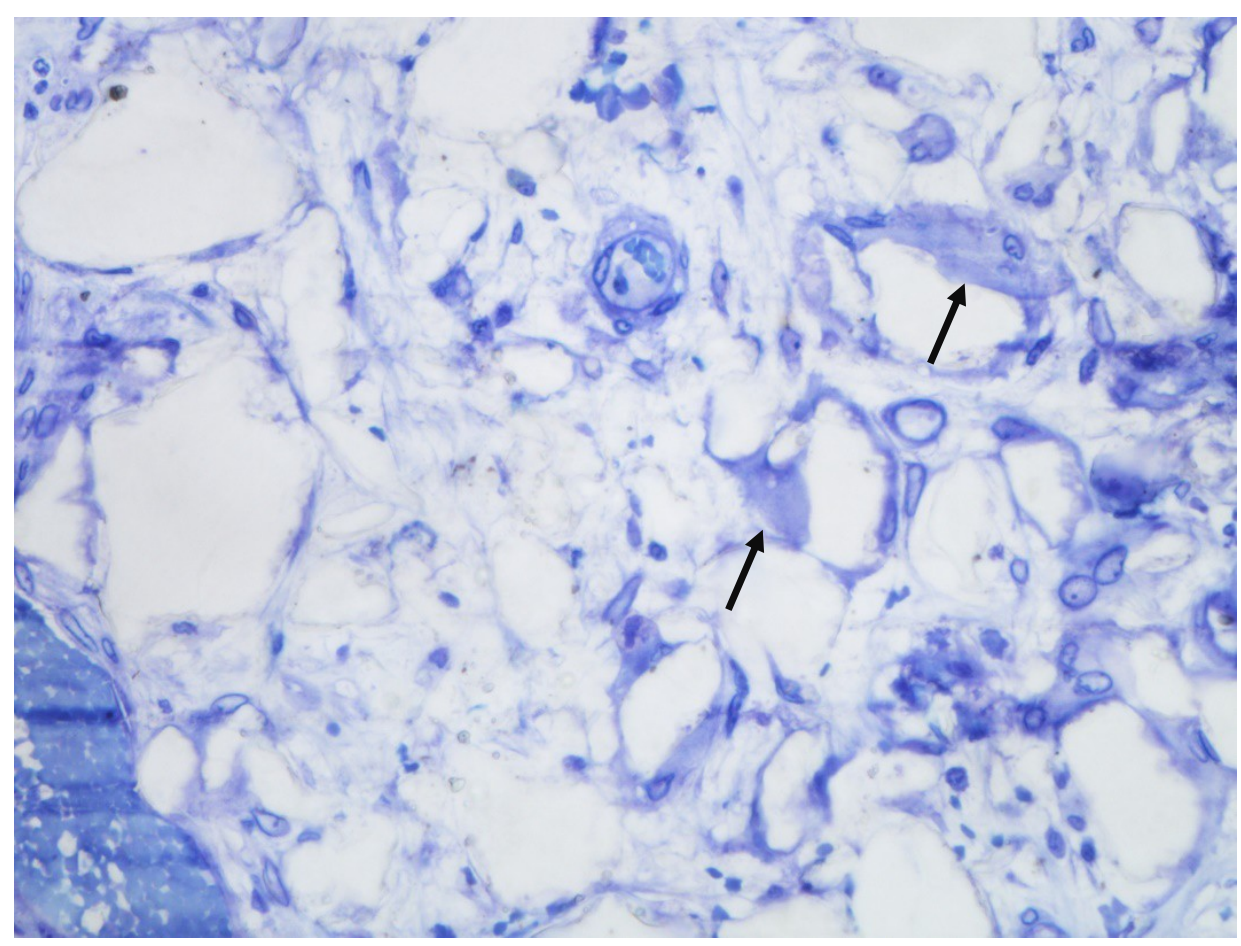


Figure 11: Vascularized fibrous tissue can be seen between the bulk material (black arrow) and smaller pieces of implant material (red arrows) seen as voids (section 18-033-6A; animal 59-146L). Toluidine Blue; original magnification, 100X.

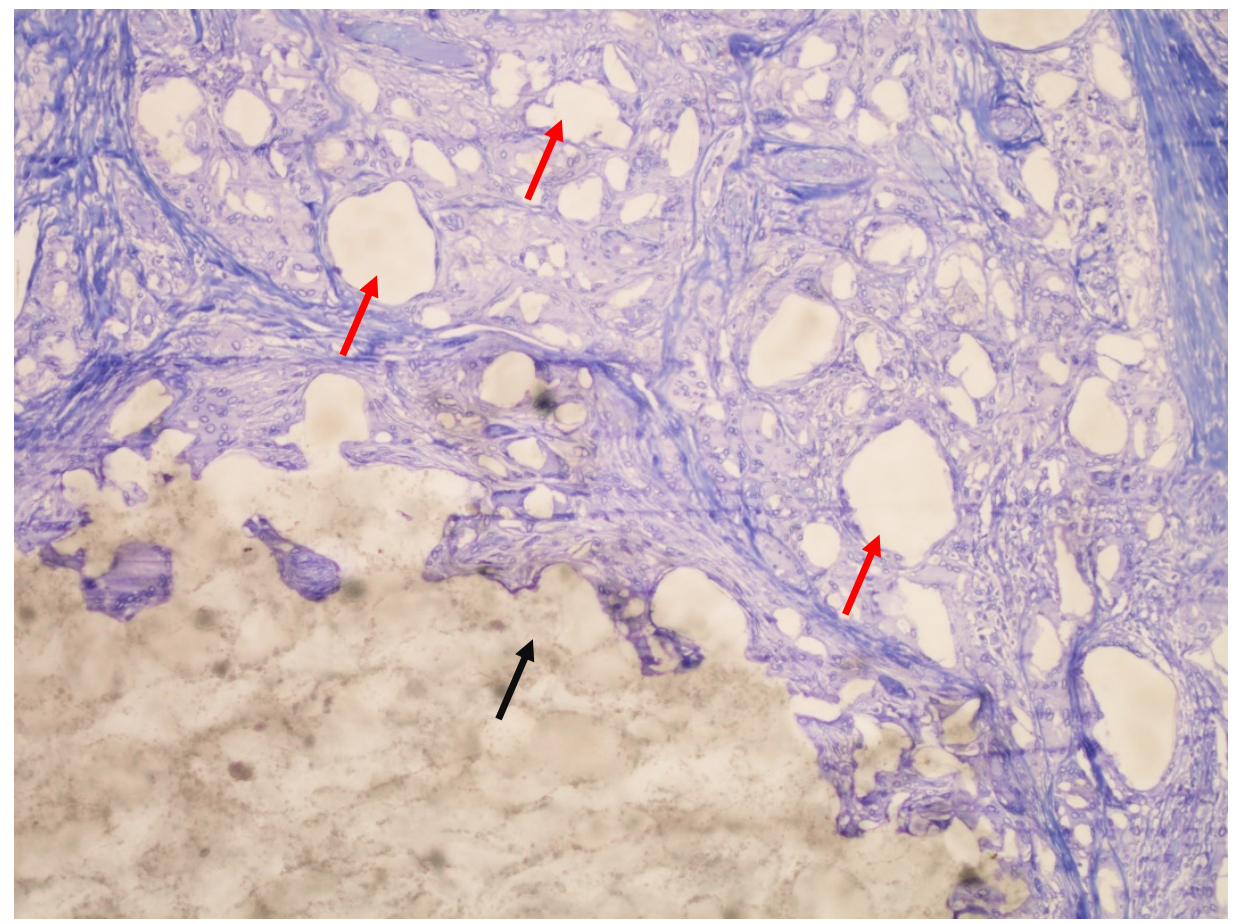

